\title{
An alternative solvent system for the steady state electrospinning of polycaprolactone
}

Lien Van der Schueren ${ }^{1 *}$

lien.vanderschueren@ugent.be

$\mathbf{T}+3292645740$

F +3292645846

Bert De Schoenmaker ${ }^{1}$

bert.deschoenmaker@ugent.be

Özlem I Kalaoglu ${ }^{1}$

Karen De Clerck ${ }^{1}$

karen.declerck@ugent.be

${ }^{1}$ Ghent University

Department of Textiles

Technologiepark 907

B-9052 Zwijnaarde (Ghent)

Belgium

\section{Abstract}

Polycaprolactone (PCL) is a biocompatible aliphatic polyester with many possible applications in the medical field. PCL nanofibres, produced by electrospinning, could provide new characteristics that are of interest for these applications. However, a key prerequisite is the ability to obtain bead-free fibres with diameters in the nanoscale range. At present the most commonly used solvent for electrospinning PCL is chloroform, but this only leads to fibres in the microscale range. Therefore various solvent systems were examined in this study. The innovative solvent mixture formic acid/acetic acid was found to allow for nanofibres with a diameter ten times smaller than chloroform. Moreover, steady state conditions could be obtained which thus allow electrospinning in a stable and reproducible way. Further it was noticed that the average fibre diameter decreased with decreasing polymer concentration while the diameter distribution decreased with increasing amount of formic acid. Also the humidity, an often overlooked yet important parameter, was noted to affect both diameter 
characteristics. Generally it can be concluded that the solvent system formic acid/acetic acid could fill the gap in electrospinning PCL since it is readily able to produce uniform fibres in the nanoscale range.

Keywords electrospinning, nanofibres, polycaprolactone, steady state

\section{Introduction}

Polycaprolactone (PCL) is one of the most commonly applied synthetic polymers for medical use because of its biocompatibility and slow biodegradability [1,2,3]. By combining the favourable intrinsic properties of the polymer PCL with the unique characteristics of a nanofibrous structure a promising material for biomedical applications can be obtained [4-6]. Nanofibrous structures show a large specific surface area, a small pore size and a high porosity which render them of interest in a wide variety of medical applications [7].

Currently electrospinning is the only well established technique capable of producing nanofibrous structures in a continuous way [8]. In electrospinning an electric field is applied between a grounded collector plate and the tip of a nozzle through which the polymer solution is flowing. Due to the electrostatic forces the polymer solution is distorted from a spherical pendant drop to a Taylor cone. Once these forces overcome the surface tension of the polymer solution a jet is drawn from the tip of the Taylor cone which is subsequently elongated due to bending and splaying. As a result a nonwoven is deposited on the collector plate.

A number of studies have been devoted to the electrospinning of PCL. However, obtaining bead-free fibres with diameters in the nanoscale range appeared to be difficult [4,6,9-15]. For medical applications it is nevertheless essential to have fibre diameters in this range in order to mimic the natural extra cellular matrix morphology and thus to promote optimal cell growth [16]. Chloroform is most often applied as solvent for electrospinning PCL but produces rather microfibres instead of nanofibres as the diameters are typically 3 to $5 \mu \mathrm{m}$ $[15,17]$. Other relatively highly toxic solvents such as dimethylformamide (DMF), tetrafluoroethylene, methylene chloride, dichloroethane and pyridine have been reported as well [4,6,18-22]. Some of them allow for nanofibres with diameters in the nanoscale range but in none of the reported systems attention was given to the stability nor the reproducibility of the electrospinning process. These are nevertheless essential for a potential breakthrough of the system. Steady state electrospinning is reported for other polymers as a solution for obtaining a high stability and reproducibility [23,24]. This steady state implies a continuously 
stable Taylor cone as a function of time together with an equal amount of polymer that is transported through the needle per time unit to the amount that is deposited as fibres on the collector plate per time unit [23]. The steady state condition requires stability of the process in time and is thus more strict than the common conditions for stable electrospinning described in literature so far [4,25-28]. It guarantees not only beadless nanofibrous structures but also a high reproducibility.

The major objective of this study is to determine a new solvent system which generates nanofibres in the nanoscale range, thus far below the micrometre range obtained by using chloroform. Therefore a solvent study is performed using single and binary solvent systems. The most promising solvent system is to be studied in more detail. This consists of investigating the steady state condition as well as the influence of the electrospinning parameters on the resulting fibre morphology.

\section{Materials and Methods}

PCL and the solvents $99.8 \mathrm{v} \%$ chloroform, $98 \mathrm{v} \%$ formic acid, $99.8 \mathrm{v} \%$ acetic acid, $99.8 \mathrm{v} \%$ methanol and 99.8 wt\% ethanol were supplied by Sigma Aldrich. Also silica gel orange was purchased from Sigma Aldrich. The electrospun solutions were prepared by dissolving a certain amount of PCL pellets in various solvent systems. The solutions were magnetically stirred at room temperature for three hours, which was needed for complete dissolution. The viscosity of the solutions obtained was measured using a Brookfield viscometer LVDV-II. The conductivity was measured with a CDM210 conductivity meter (Radiometer Analytical).

During the electrospinning process, the polymer solution was pumped from a $20 \mathrm{ml}$ syringe into a $15.24 \mathrm{~cm}$ long needle with an inner diameter of $1.024 \mathrm{~mm}$. A KD Scientific Syringe Pump Series 100 regulated the flow rate of the solution. The voltage was adjusted using a Glassman High Voltage Series EH source. All electrospinning was performed at room temperature $\left(22 \pm 2{ }^{\circ} \mathrm{C}\right)$. The electrospinning experiments at a relative humidity (RH) of $30 \pm$ $5 \%$ and $50 \pm 5 \%$ were performed in a conditioned lab. The electrospinning experiments at a $\mathrm{RH}$ of $10 \pm 4 \%$ were performed in a closed in-house build chamber in which the air was dried with silica, Fig. 1. Before and during the electrospinning process the humidity was monitored by a Vaisala humidity probe. 
The molecular weight of PCL was determined by GPC measurements on a Shimadzu system equipped with a SCL-10A system controller, a LC-10AD pump, a RID-10A refractive index detector and a PL gel $5 \mu \mathrm{m}$ Mixed-D column utilizing hexafluorisopropanol as eluent at a flow rate of $1 \mathrm{ml} \mathrm{min}^{-1}$ and polymethylmethacrylate as standard.

The morphology of the electrospun structures was examined using a Scanning Electron Microscope (FEI QUANTA 200 F). Prior to the SEM-measurements, the sample was coated with gold using a sputter coater (Balzers Union SCD 030). Fifty diameter measurements on each sample using Cel1^D software (Olympus) determined the average fibre diameter.

The steady state condition was judged by visually checking the stability of the Taylor cone during 30 minutes and by verifying the absence of droplets and/or beads on SEM images. The steady state conditions were next presented in a steady state table in which the solution parameters solvent ratio and polymer concentration were varied on the $x$ - and $y$-axis respectively. All other electrospinning parameters were kept constant, except for one, in this study the applied voltage, which was varied to establish steady state. This allowed for the demarcation of a steady state area within the steady state table presenting the possible combinations of solvent ratio and polymer concentration for which steady state is possible. The value for the applied voltage was noted within the steady state area of the table and represents a range of voltages, typically $\pm 1 \mathrm{kV}$, allowing for steady state electrospinning.

\section{Results and Discussion}

\section{Solvent study}

In order to determine an optimum solvent system for electrospinning PCL, different single and binary solvent systems were studied. Besides being soluble in chloroform, PCL is soluble in a whole range of solvents. Formic acid and acetic acid are part of this range and are the least toxic. Moreover formic acid is often used for electrospinning various polymers in literature [29-33]. A combination formic acid/acetic acid is less exploited but showed to be very promising for polyamide 6 [34]. Therefore focus in this paper is to be given to formic acid and acetic acid as an alternative to chloroform. Methanol and ethanol are in some studies added to the chloroform solution to improve the electrospinnability [35-37]. Therefore these alcohols, which are no solvents of PCL, were also added to formic and acetic acid. Table 1 gives an overview of all solvent systems studied in this paper. 
The polymer concentration was fixed at $10 \mathrm{wt} \%$ and the $\mathrm{RH}$ at $30 \%$ for all systems. When using a binary solvent system three solvent compositions were examined being 1:3, 1:1 and 3:1. However, in Table 1 only one composition is shown. The flow rate was varied between 1 and $5 \mathrm{ml} \mathrm{h}^{-1}$, the tip to collector distance between 6 and $14 \mathrm{~cm}$ and the voltage between 10 and $30 \mathrm{kV}$. This allowed for a screening whether electrospinning was possible with the solvent system studied and if so, which conditions were the most optimal for further detailed studies. The results of this analysis, summarized in Table 1 and Fig. 2, show that chloroform led to uniform yet thick fibres in the microscale instead of the nanoscale range, in agreement with literature $[12,15,16]$. Acetic acid as solvent was not able to electrospin any fibrous material while formic acid resulted in a structure mainly composed out of droplets. The binary system formic acid/chloroform resulted in fibres smaller than $500 \mathrm{~nm}$ but quite some beads were noticeable. On the other hand the system formic acid/acetic acid showed fibres in the nanoscale range and only a few beads. The fibres obtained by using this solvent system were more than ten times smaller as the ones obtained when using chloroform. This new system may thus lead to a major breakthrough in electrospinning PCL since substantially smaller fibres can be obtained using less harmful solvents.

Prior to the profound study of the system PCL in formic acid/acetic acid the degradation behaviour of PCL in this solvent mixture should be known. It is essential to be able to electrospin with a stable solution for an acceptable period of time. Therefore, two 14 wt $\%$ polymer solutions with 30 and $40 \mathrm{v} \%$ acetic acid were electrospun and GPC measurements were performed on the resulting nonwovens. Comparing the thus obtained molecular weights with the molecular weight of the PCL pellets used to prepare the solutions, showed that the molecular weight did not decrease significantly after electrospinning, Table 2. Viscosity measurements as a function of time on the $40 \mathrm{v} \%$ acetic acid polymer solution (Fig. 3) moreover showed that the viscosity of the solution remained stable for up to three hours after dissolving the PCL. This implies a suitable time frame for electrospinning with a stable solution of PCL.

\section{Steady state conditions}

Based on the outcome of the solvent study, the binary solvent system formic acid/acetic acid was chosen to study in more detail. As to refine the electrospinning the steady state conditions were studied, Table 3. For the set up of this table, the polymer concentration was varied between 10 and $20 \mathrm{wt} \%$ and the acetic acid concentration between 0 and $90 \mathrm{v} \%$. The applied 
voltage was adjusted as to obtain steady state while all other electrospinning parameters were kept constant. These parameters were well chosen as to obtain the maximum steady state area. This was possible based on the preliminary results during the solvent study. Thus the flow rate was set at $1 \mathrm{ml} \mathrm{h}^{-1}$, the tip to collector distance (TCD) at $12.5 \mathrm{~cm}$ and the relative humidity at $30 \% \mathrm{RH}$. It is important to keep in mind that if one of these parameters would change, the resultant steady state table would be altered as well. For example, a TCD of 10 $\mathrm{cm}$ would also allow for steady state electrospinning but the steady state area would be smaller, as this TCD resulted in more irregularities, Fig. 4. However, the general outcome and results would be similar to the ones obtained with the parameter set used in this study.

The thus obtained steady state conditions (Table 3) show that electrospinning in steady state is possible, however only for a limited region of parameters. A minimum polymer concentration of $13 \mathrm{wt} \%$ was necessary since otherwise the viscosity of the solution was too low. At these low concentrations the entanglements between the polymer chains were not able to provide a stable jet and droplets were formed. Above $17 \mathrm{wt} \%$ the viscosity of the solution became too high and electrospinning was no longer possible since solidification of the polymer happened too fast, thus in some cases blocking the needle outlet.

As was already clear from the solvent study, it was not realizable to electrospin in steady state with pure formic acid nor pure acetic acid. A mixture of both solvents was essential for obtaining this steady state condition as a minimum concentration of $30 \mathrm{v} \%$ formic acid and 10 $\mathrm{v} \%$ acetic acid was necessary for steady state electrospinning (Table 3). This might be attributed to the relatively high dielectric constant of formic acid $\left(57.2 \varepsilon_{0}\right.$ at $\left.298 \mathrm{~K}\right)$ and the relatively low dielectric constant of acetic acid ( $6.6 \varepsilon_{0}$ at $\left.298 \mathrm{~K}\right)$ [38]. A highly polar solvent such as formic acid experiences a major influence of the electric field applied during electrospinning which causes reorientation of the solvent molecules. However, this rearrangement of molecules is dependent on the position in the electrospinning process thereby eventually giving rise to instabilities. This agrees with the reported instabilities observed in literature while electrospinning polyamide 6.6 in pure formic acid [23]. On the other hand the conductivity of a polymer solution composed of pure acetic acid is too low which also results in unstable electrospinning [24]. This finding is in agreement with earlier studies in which conductive additives were used in order to increase the conductivity of poorly polar solvents and thus to improve the electrospinning process [39]. By combining 
acetic and formic acid a solvent system with intermediate polarity is formed and stable electrospinning in time is more likely.

Within the steady state area in Table 3 the voltage variations needed to obtain steady state are noteworthy. At a constant polymer concentration (14 wt\% PCL) the voltage increased with decreasing acetic acid concentration from $10 \mathrm{kV}$ at $70 \mathrm{v} \%$ acetic acid to $18 \mathrm{kV}$ at $10 \mathrm{v} \%$ acetic acid. This can be explained by the conductivity increase from $0.004 \mathrm{mS} \mathrm{m}^{-1}$ (70 v\% acetic acid) to $0.089 \mathrm{mS} \mathrm{m}^{-1}(10 \mathrm{v} \%$ acetic acid). This rise in conductivity with decreasing acetic acid content is in agreement with variations in conductivity found in literature [40]. However at a fixed solvent ratio (40 v\% acetic acid) the voltage remained constant at $15 \mathrm{kV}$ as the polymer concentration increased which is in line with the constant conductivity at 0.030 $\mathrm{mS} \mathrm{m}^{-1}$ at $40 \mathrm{v} \%$ acetic acid. Thus, the solvent ratio is the dominant factor determining the conductivity and consequently the required voltage. This might be expected since the solvents itself carry the highest amount of charges and PCL has only a minor contribution to it as shown by the conductivity measurements.

\section{Study of the fibre morphology}

After the study of the steady state conditions the focus in this section is given to the influence of the main electrospinning parameters on the fibre morphology of samples prepared under steady state. These parameters are generally divided in three groups being process, solution and ambient parameters. The TCD and flow rate are the most important process parameters but the solvent study revealed that steady state was only possible between strict borders of TCD and flow rate. Therefore, it was chosen not to devote further attention to a variation of these parameters but to keep them constant at the already set values. The solution parameters solvent ratio and polymer concentration as well as the ambient parameter relative humidity can vary in a broader range and were thus of interest to study in more detail.

The effect of the solvent composition on the fibre morphology of the resulting nonwoven was investigated by varying the acetic acid concentration from $10 \mathrm{v} \%$ to $80 \mathrm{v} \%$, this at $14 \mathrm{wt} \%$ PCL and a RH of $10 \%$. Although $80 \mathrm{v} \%$ of acetic acid is not part of the steady state region at $10 \% \mathrm{RH}$, it does allow electrospinning in a stable way for a limited period of time and can thus be included. With this, it is important to realize that in order to allow stable electrospinning the applied voltage was not constant during electrospinning this range (similar to Table 3). All produced nonwovens show uniform bead-free fibres as seen in the SEM 
images in Fig. 5. The average fibre diameter shows only a minor increasing trend from 545 $\mathrm{nm}$ at $10 \mathrm{v} \%$ acetic acid to $662 \mathrm{~nm}$ at $80 \mathrm{v} \%$ acetic acid as shown in Fig. 6. However, particularly prominent in Fig. 6 is the increasing standard deviation with increasing amount of acetic acid. The percent deviation rises from $17 \%$ at $10 \mathrm{v} \%$ acetic acid to $64 \%$ at $80 \mathrm{v} \%$ acetic acid. As the viscosity is not affected by the solvent composition, Fig. 7, these effects must be attributed to the changes in the conductivity with varying acetic acid concentration. It is known that the average fibre diameter increases with decreasing conductivity $[23,41,42]$. However, in this study the observed effect is small due to the varying voltage needed for electrospinning the whole range. Also the broadening of the fibre diameter distribution with a decrease in conductivity is in line with previous investigations on other polymers $[41,43]$ and is likely caused by the more inhomogeneous charge distribution in solvents with low conductivity such as acetic acid.

The second main solution parameter to investigate was the polymer concentration. Since the previous results showed that the smallest standard deviation was obtained with $10 \mathrm{v} \%$ of acetic acid, this solvent composition was chosen and a voltage of $18 \mathrm{kV}$ was applied. The $\mathrm{RH}$ was again set at $10 \%$. The PCL concentration was varied from 12 to $17 \mathrm{wt} \%$. Again, although 12 and $13 \mathrm{wt} \%$ do not belong to the steady state region, stable electrospinning was possible for a certain period. SEM images of 12 and $17 \mathrm{wt} \%$ PCL are presented in Fig. 8. The average fibre diameters in Table 4 demonstrate the increase in diameter with increasing polymer concentration from $297 \mathrm{~nm}(12 \mathrm{wt} \%)$ to $966 \mathrm{~nm}(17 \mathrm{wt} \%)$. This is due to the rise in viscosity when the amount of PCL increases, Fig. 9. The higher amount of entanglements discourages the bending stability of the jet to set in for a longer distance from the needle thereby causing thicker fibres [44,45]. Moreover, at higher polymer concentrations a faster solidification of the jet is realized since the critical amount of solvent necessary to dissolve all polymer is reached earlier in the process [23].

RH is an often overlooked, though important parameter which is known to have an influence on the fibre morphology [46-48]. To study the effect of the RH the nonwovens with varying polymer concentration were also produced at $50 \% \mathrm{RH}$. It was noticed that the time to stabilize the electrospinning process increased significantly at this higher humidity. However, at the time of sample production for SEM measurements, the Taylor cone was visually stable. The results in Table 4 show that the average fibre diameter decreases with increasing humidity. This is likely mainly caused by the plasticizing effect of water which causes a 
slower solidification and thus a longer period of jet thinning and is in agreement with observations in other polymer-solvent systems [46,49]. Yet, another possible cause may be found in a variation of the solution parameters during electrospinning at different $\mathrm{RH}$ [50]. The standard deviations in Table 4 further suggest that the deviation increases when the humidity rises. This trend could be confirmed at other acetic acid concentrations and might be attributed to the different effect of the humidity in the polymer jet due to differences in accessibility depending on the position of the molecules in the jet. Although this hypothesis of increasing deviation with increasing humidity has escaped examination in literature, calculations on fibre diameters of electrospun polyethylene oxide and polylactic acid nanofibres found in literature show a similar trend $[47,48]$.

\section{Conclusion}

A solvent study with single and binary solvent systems revealed the major potential of the solvent mixture formic acid/acetic acid for electrospinning PCL. Fibres with diameters more than ten times smaller than the ones obtained with the most commonly applied solvent chloroform could be produced. Moreover, the stability and reproducibility of the produced nonwovens was guaranteed by setting up a steady state table. The steady state conditions show that a minimum concentration of $30 \mathrm{v} \%$ formic acid and $10 \mathrm{v} \%$ acetic acid is necessary for steady state electrospinning. Further it was found that the polymer concentration is the dominant factor for the resulting average fibre diameter. The standard deviation of the nanofibres was lowered at high formic acid content and low RH. In conclusion, the solvent system formic acid/acetic acid has proven to be an excellent system for electrospinning PCL under steady state conditions and can produce fibres in the nanoscale range with a small diameter distribution. This is a major breakthrough compared to the other solvent systems for PCL reported up till now.

\section{References}

[1] Agarwal S, Wendorff JH, Greiner A. Use of electrospinning technique for biomedical applications. Polymer 2008;49(26):5603-5621

[2] Neppalli R, Marega, Marigo A, Bajgai MP, Kim HY, Causin V. Poly(epsiloncaprolactone) filled with electrospun nylon fibres: A model for a facile composite fabrication. Eur Polym J 2010;46(5):968-976 
[3] Venugopal J, Zhang YZ, Ramakrishna S. Fabrication of modified and functionalized polycaprolactone nanofibre scaffolds for vascular tissue engineering. Nanotechnology 2005;16(10):2138-2142

[4] Lee KH, Kim HY, Khil MS, Ra YM, Lee DR. Characterization of nano-structured poly(epsilon-caprolactone) nonwoven mats via electrospinning. Polymer 2003;44(4):12871294

[5] Duan Y, Jia J, Wang S, Yan W, Jin L, Wang Z. Preparation of antimicrobial poly(epsiloncaprolactone) electrospun nanofibers containing silver-loaded zirconium phosphate nanoparticles. J Appl Polym Sci 2007;106(2):1208-1214

[6] Moghe AK, Hufenus R, Hudson SM, Gupta BS. Effect of the addition of a fugitive salt on electrospinnability of poly(epsilon-caprolactone). Polymer 2009;50(14):3311-3318

[7] Xie J, Li X, Xia Y. Putting Electrospun Nanofibers to Work for Biomedical Research. Macromol Rapid Comm 2008;29(22):1775-1792

[8] Greiner A, Wendorff JH. Electrospinning: A fascinating method for the preparation of ultrathin fibres. Angew Chem Int Ed 2007;46(30):5670-5703

[9] Li W, Tuli R, Okafor C, Derfoul A, Danielson KG, Hall DJ, Tuan RS. A threedimensional nanofibrous scaffold for cartilage tissue engineering using human mesenchymal stem cells. Biomaterials 2005;26(6):599-609

[10] Shin M, Ishii O, Sueda T, Vacanti JP. Contractile cardiac grafts using a novel nanofibrous mesh. Biomaterials 2004;25(17):3717-3723

[11] Gaumer J, Prasad A, Lee D, Lannutti J. Structure-function relationships and source-toground distance in electrospun polycaprolactone. Acta Biomater 2009;5(5):1552-1561

[12] Del Gaudio C, Bianco A, Folin M, Baiguera S, Grigioni M. Structural characterization and cell response evaluation of electrospun PCL membranes: Micrometric versus submicrometric fibers. J Biomed Mater Res A 2009;89A(4):1028-1039

[13] Yu H, Jang J, Kim T, Lee H, Kim H. Apatite-mineralized polycaprolactone nanofibrous web as a bone tissue regeneration substrate. J Biomed Mater Res A 2009;88A(3):747-754

[14] Li X, Xie J, Yuan X, Xia Y. Coating Electrospun Poly(E-caprolactone) Fibers with Gelatin and Calcium Phosphate and Their Use as Biomimetic Scaffolds for Bone Tissue Engineering. Langmuir 2008;24(24):14145-14150

[15] Lowery JL, Datta N, Rutledge GC. Effect of fiber diameter, pore size and seeding method on growth of human dermal fibroblasts in electrospun poly(epsilon-caprolactone) fibrous mats. Biomaterials 2010;31(3):491-504 
[16] Smith LA, Ma PX. Nanofibrous scaffolds for tissue engineering. Colloid Surface B 2004;39(3):125-131

[17] Del Gaudio C, Grigioni M, Bianco A, De Angelis G. Electrospun bioresorbable heart valve scaffold for tissue engineering. Int J Artif Organs 2008; 31(1):68-75

[18] Hsu C, Shivkumar S. N,N-Dimethylformamide Additions to the Solution for the Electrospinning of Poly(epsilon-caprolactone) Nanofibers. Macromol Mater Eng 2004;289(4):334-340

[19] Kim JH, Choung P, Kim IY, Lim KT, Son HM, Choung Y, Cho C, Chung JH. Electrospun nanofibers composed of poly(epsilon-caprolactone) and polyethylenimine for tissue engineering applications. Mat Sci Eng C-Bio S 2009;29(5):1725-1731

[20] Prabhakaran MP, Venugopal J, Chan CK, Ramakrishna S. Surface modified electrospun nanofibrous scaffolds for nerve tissue engineering. Nanotechnology 2008;19(45):1725-1731 [21] Edwards MD, Mitchell GR, Mohan SD, Olley RH. Development of orientation during electrospinning of fibres of poly(epsilon-caprolactone). Eur Polym J 2010;46(6):1175-1183 [22] Kariduraganavar MY, Davis FJ, Mitchell GR, Olley RH. Using an additive to control the electrospinning of fibres of poly(epsilon-caprolactone). Polym Int 2010;59(6):827-835

[23] De Vrieze S, Westbroek P, Van Camp T, De Clerck K. Solvent System for Steady State Electrospinning of Polyamide 6.6. J Appl Polym Sci 2010;115(2):837-842

[24] De Vrieze S, De Schoenmaker B, Ceylan Ö, Depuydt J, Van Landuyt L, Rahier H, Van Assche G, De Clerck K. Morphologic study of steady state electrospun polyamide 6 nanofibres. J Appl Polym Sci 2011;119(5):2984-2990

[25] Kim G, Cho YS, Kim WD. Stability analysis for multi jets electrospinning process modified with a cylindrical electrode. Eur Polym J 2006;42(9):2031-2038

[26] Carroll CP, Joo YL. Axisymmetric instabilities in electrospinning of highly conducting, viscoelastic polymer solutions. Phys Fluids 2009;21(10):103101-103111

[27] Zuo W, Zhu M, Yang W, Yu H, Chen Y, Zhang Y. Experimental study on relationship between jet instability and formation of beaded fibers during electrospinning. Polym Eng Sci 2005;45(5):704-709

[28] Fong H, Chun I, Reneker DH. Beaded nanofibers formed during electrospinning. Polymer 1999;40(16):4585-4592

[29] Ryu YJ, Kim HY, Lee KH, Park HC, Lee DR. Transport properties of electrospun nylon 6 nonwoven mats. Eur Polym J 2003;39(9):1883-1889

[30] Behler K, Havel M and Gogotsi Y. New solvent for polyamides and its application to the electrospinning of polyamides 11 and 12. Polymer 2007;48(22):6617-6621 
[31] Weiss J, Wongsasulak S, Kit KM, McClements DJ, Yoovidhya T. The effect of solution properties on the morphology of ultrafine electrospun egg albumen-PEO composite fibers. Polymer 2007;48(2):448-457

[32] Ki CS, Baek DH, Gang KD, Lee KH; Um IC; Park YH. Characterization of gelatin nanofiber prepared from gelatin-formic acid solution. Polymer 2005;46(14):5094-5102

[33] Heikkila P, Harlin A. Parameter study of electrospinning of polyamide-6. Eur Polym J 2008;44(10):3067-3079

[34] Daels N, De Vrieze S, Decostere B, Dejans P, Dumoulin A, De Clerck K, Westbroek P, Van Hulle S. The use of electrospun flat sheet nanofibre membranes in MBR applications. Desalination 2010.257(1-3):170-176

[35] Tan EPS, Ng SY, Lim CT. Tensile testing of a single ultrafine polymeric fiber. Biomaterials 2005;26(13):1453-1456

[36] Wang Y, Wang B, Wang G, Yi T, Yu Q. Nucleating agent induced impact fracture behavior change in PP/POE blend. Polym Bull 2009;63(2):259-265

[37] Pektok E, Nottelet B, Tille JC, Gurny R, Kalangos A, Moeller, Walpoth BH. Degradation and Healing Characteristics of Small-Diameter Poly(epsilon-Caprolactone) Vascular Grafts in the Rat Systemic Arterial Circulation. Circulation 2008;118(24): 2563-2570

[38] Dean, J. Lange's Handbook of Chemistry, 15th ed.; McGraw-Hill: New York, 1998.

[39] Arumugam GK, Khan S, Heiden PA. Comparison of the Effects of an Ionic Liquid and Other Salts on the Properties of Electrospun Fibers, 2-Poly(vinyl alcohol). Macromol Mater Eng 2009;294(1):45-53

[40] Supaphol1 P, Mit-Uppatham C, Nithitanakul M. Ultrafine electrospun polyamide-6 fibers: Effect of emitting electrode polarity on morphology and average fiber diameter. Macromol Mater Eng 2005;290(9):933-942

[41] Son WK, Youk JH, Lee TS, Park WH. The effects of solution properties and polyelectrolyte on electrospinning of ultrafine poly(ethylene oxide) fibers. Polymer 2004;45(9):2959-2966

[42] Dong H, Nyame V, Macdiarmid AG, Jones WE. Polyaniline/poly(methyl methacrylate) coaxial fibers: The fabrication and effects of the solution properties on the morphology of electrospun core fibers. J Polym Sci Polym Phys 2004;42(21):3934-3942

[43] Lee KH, Kim HY, La YM, Lee DR, Sung NH. Influence of a mixing solvent with tetrahydrofuran and N,N-dimethylformamide on electrospun poly(vinyl chloride) nonwoven mats. J Polym Sci Polym Phys 2002;40(19):2259-2268 
[44] Jacobs V, Anandjiwala RD, Maaza M. The Influence of Electrospinning Parameters on the Structural Morphology and Diameter of Electrospun Nanofibers. J Appl Polym Sci 2010;115(5):3130-3136

[45] Sutasinpromprae J, Jitjaicham S, Nithitanakul M, Meechaisue C, Supaphol P. Preparation and characterization of ultrafine electrospun polyacrylonitrile fibers and their subsequent pyrolysis to carbon fibers. Polym Int 2006;55(8):825-833

[46] De Vrieze S, Van Camp T, Nelvig A, Hagström B, Westbroek P, De Clerck K. The effect of temperature and humidity on electrospinning. J Mater Sci 2009;44(5):1357-1362

[47] Medeiros ES, Mattoso LHC, Offeman RD, Wood DF, Orts WJ. Effect of relative humidity on the morphology of electrospun polymer fibers. Can J Chem 2008;86(6):590-599 [48] Tripatanasuwan S, Zhong Z, Reneker DH. Effect of evaporation and solidification of the charged jet in electrospinning of poly(ethylene oxide) aqueous solution. Polymer 2007;48(19):5742-5746

[49] Antolini E. Effect of moisture on some properties of lithium chloride-poly(epsiloncaprolactam) mixtures. J Mater Sci 1997;16(22):1797-1800

[50] Marsano E, Francis L, Giunco F. Polyamide 6 nanofibrous nonwovens via electrospinning. J Appl Polym Sci 2010;117(3):1754-1765 


\section{Figures}

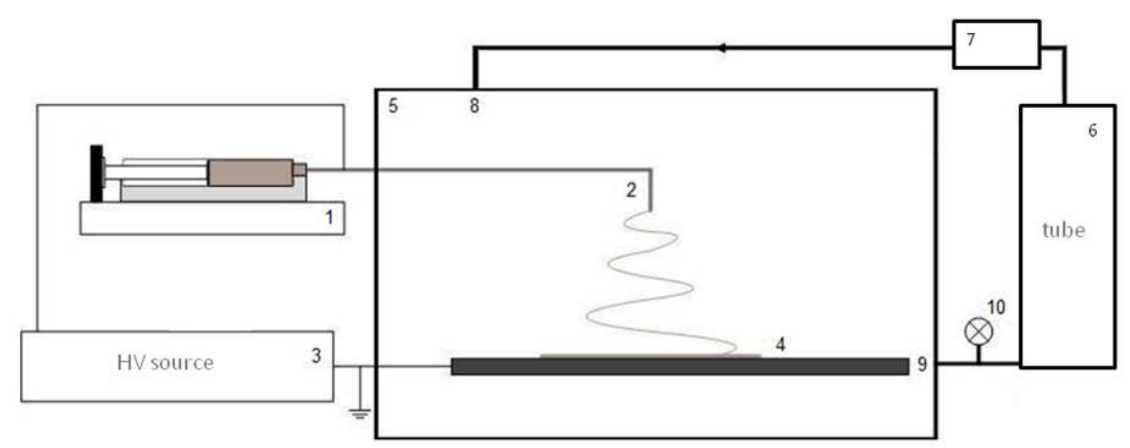

Fig. 1. Scheme of the humidity controlled electrospinning setup used for electrospinning at 10 \% RH. (1) pump, (2) needle, (3) high voltage source, (4) collector plate, (5) closed chamber, (6) tube filled with silica orange, (7) pump, (8) inlet airflow, (9) outlet airflow, (10) humidity sensor
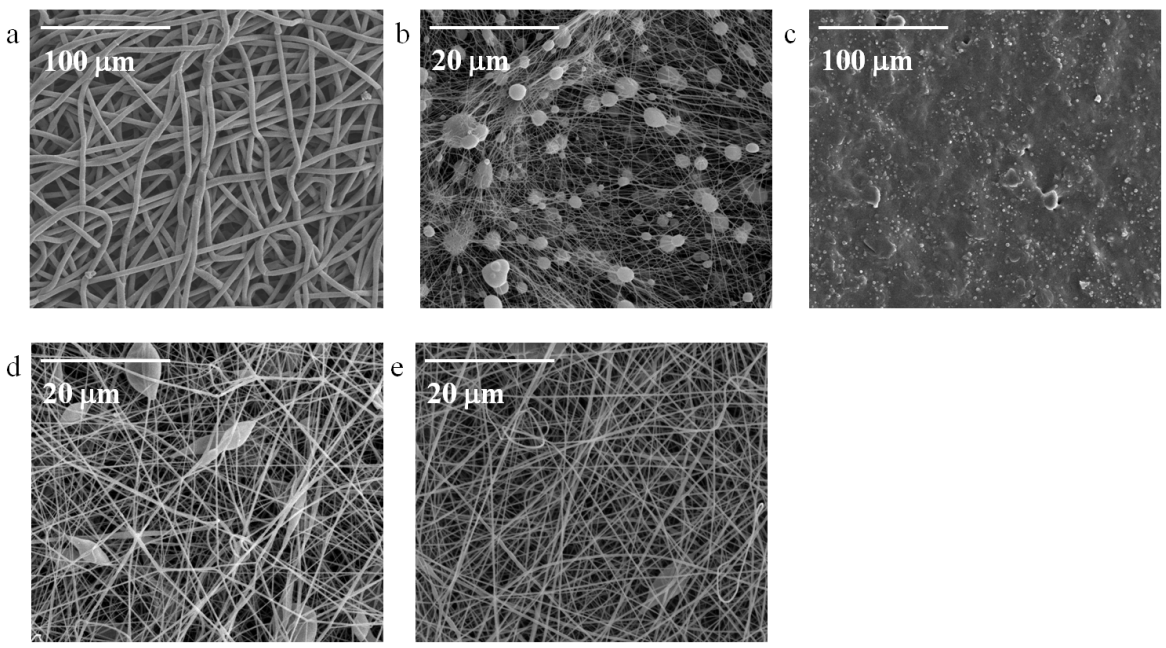

Fig. 2. SEM images for various solvent systems (a) chloroform, (b) formic acid, (c) acetic acid, (d) formic acid/chloroform (3:1), (e) formic acid/acetic acid (1:3), produced at $30 \% \mathrm{RH}$ 


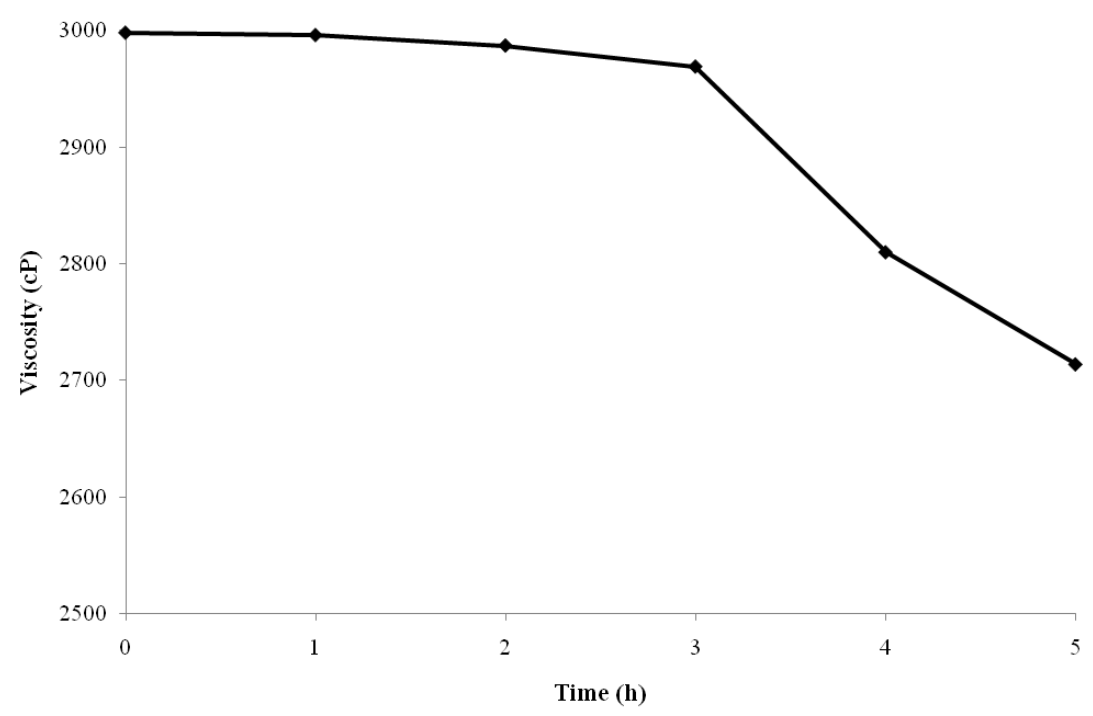

Fig. 3. Viscosity of a $14 \mathrm{wt} \%$ PCL in $40 \mathrm{v} \%$ acetic acid solution as a function of time after dissolving PCL in the solvent system
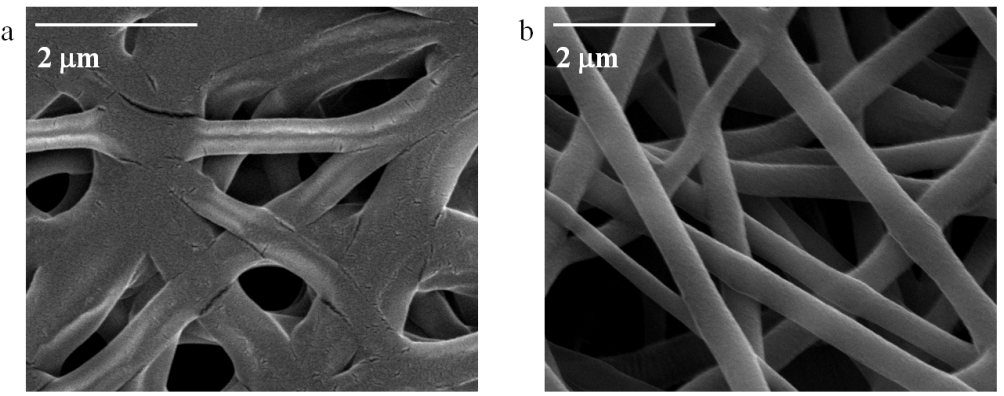

Fig. 4. SEM image of $14 \mathrm{wt} \%$ PCL in $40 \mathrm{v} \%$ acetic acid (a) with a TCD of $10 \mathrm{~cm}$, (b) with a TCD $12.5 \mathrm{~cm}$, produced at $30 \% \mathrm{RH}$
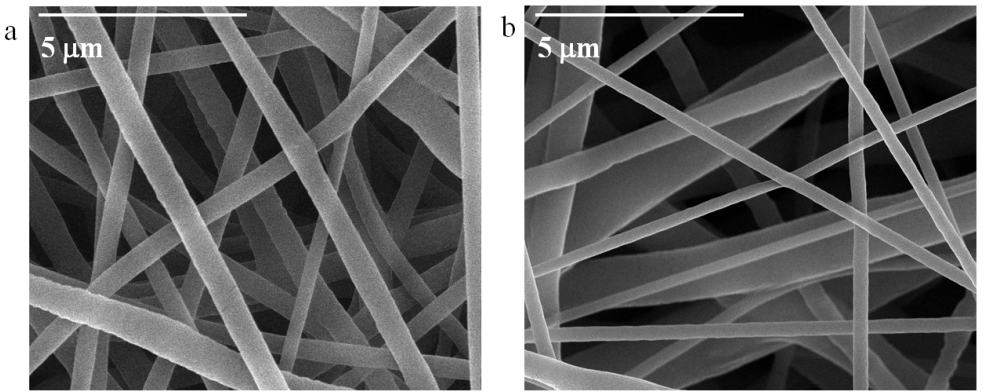

Fig. 5. SEM images of a $14 \mathrm{wt} \%$ PCL solution with (a) $10 \mathrm{v} \%$, (b) $70 \mathrm{v} \%$ acetic acid, produced at $10 \% \mathrm{RH}$ 


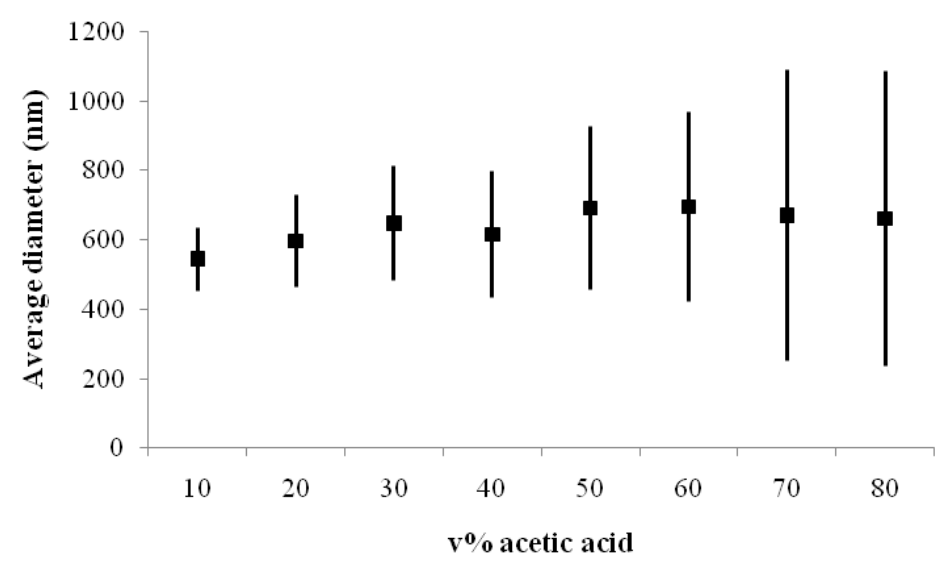

Fig. 6. Average fibre diameter of a $14 \mathrm{wt} \%$ PCL solution as a function of the acetic acid concentration, produced at $10 \% \mathrm{RH}$

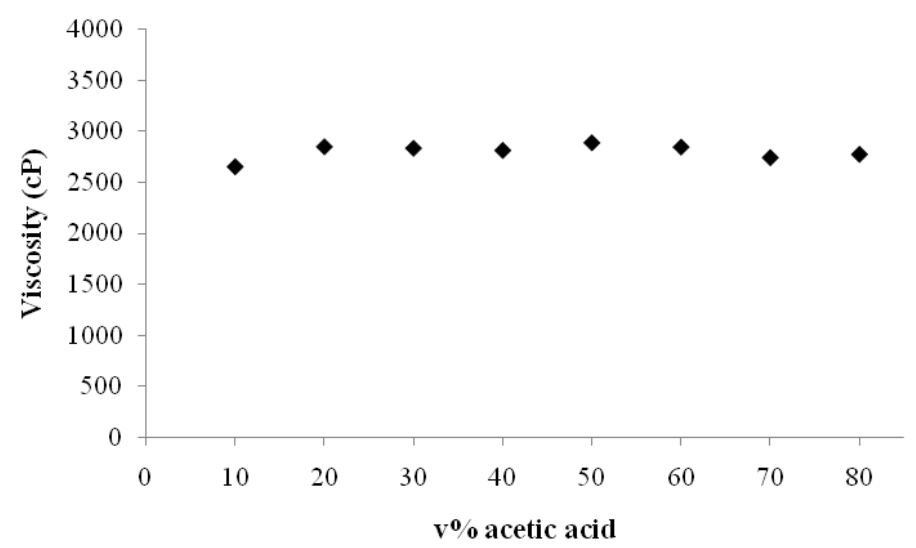

Fig. 7. Viscosity of a $14 \mathrm{wt} \%$ PCL solution as a function of the acetic acid concentration
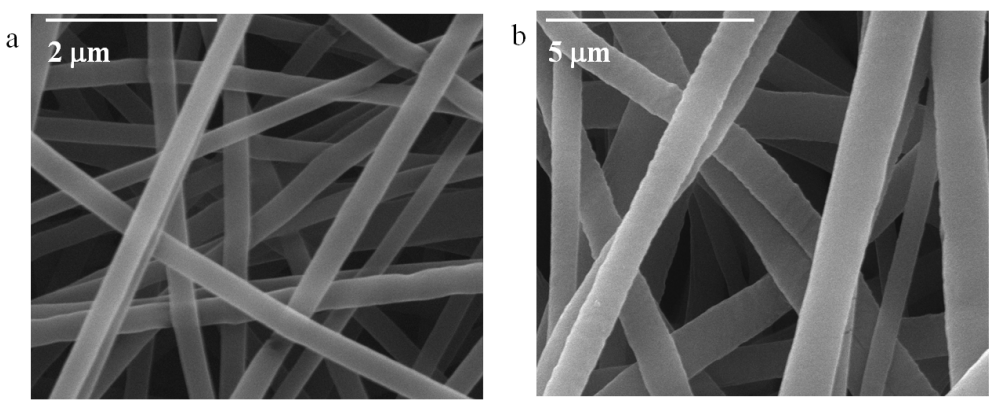

Fig. 8. SEM images of a $10 \mathrm{v} \%$ acetic acid with (a) $12 \mathrm{wt} \%$, (b) $17 \mathrm{wt} \%$ PCL, produced at 10 $\% \mathrm{RH}$ 


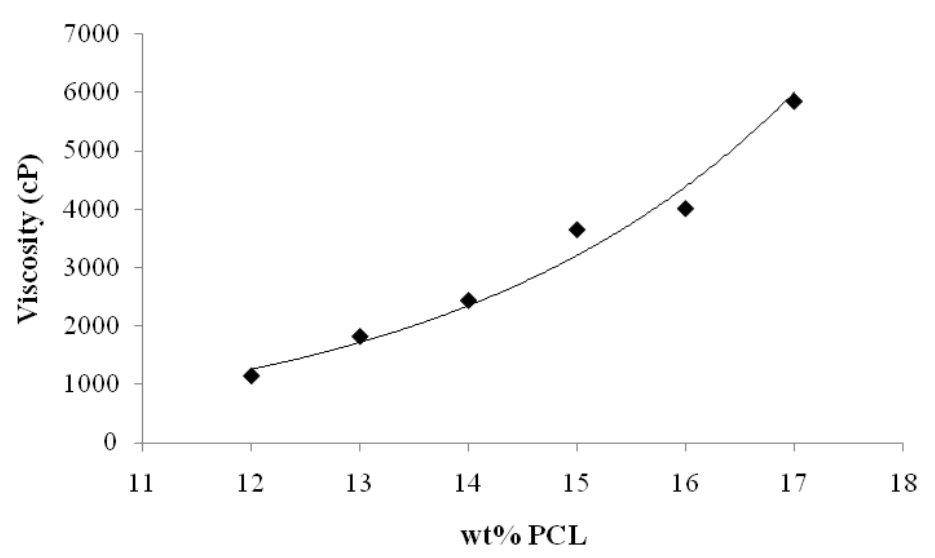

Fig. 9. Viscosity of a $10 \mathrm{v} \%$ acetic acid solution as a function of the polymer concentration

\section{Tables}

Table 1. Solubility and electrospinning results for the solvent systems used in the solvent study (concentration PCL $=10 \mathrm{wt} \%$ ), experiments performed at a $\mathrm{RH}$ of $30 \%$.

\begin{tabular}{|l|l|l|l|l|}
\hline Solvent(s) & Solubility & $\begin{array}{l}\text { Electro- } \\
\text { spinnability }\end{array}$ & $\begin{array}{l}\text { Optimal process } \\
\text { parameters }\end{array}$ & Diameter (nm) \\
\hline chloroform & + & + & $2 \mathrm{ml} \mathrm{h}^{-1} ; 10 \mathrm{~cm} ; 10 \mathrm{kV}$ & $4173 \pm 287$ \\
\hline formic acid* & + & \pm & $2 \mathrm{ml} \mathrm{h}^{-1} ; 6 \mathrm{~cm} ; 15 \mathrm{kV}$ & \\
\hline acetic acid & + & - & & \\
\hline formic acid/ethanol & + & - & & \\
\hline formic acid/methanol & + & - & & \\
\hline formic acid/chloroform & + & \pm & $1 \mathrm{ml} \mathrm{h}^{-1} ; 10 \mathrm{~cm} ; 12 \mathrm{kV}$ & $222 \pm 39$ \\
\hline acetic acid/chloroform & + & - & & \\
\hline acetic acid/ethanol & - & - & & \\
\hline acetic acid/methanol & - & - & & \\
\hline
\end{tabular}

*Spun with a polymer concentration of $13 \mathrm{wt} \%$ since the viscosity with $10 \mathrm{wt} \%$ was too low 
Table 2. GPC measurements on PCL pellet and electrospun nonwovens (14 wt\% PCL, 30 and $40 \mathrm{v} \%$ acetic acid)

\begin{tabular}{l|l|l} 
& $\mathrm{Mn}$ & $\mathrm{Mw}$ \\
\hline pellet & $114.10^{3}$ & $191.10^{3}$ \\
\hline nonwoven 30 v\% acetic acid & $113.10^{3}$ & $186.10^{3}$ \\
\hline nonwoven 40 v\% acetic acid & $105.10^{3}$ & $194.10^{3}$
\end{tabular}

Table 3. Steady state table for electrospinning PCL in formic acid/acetic acid (flow rate $=1$ $\mathrm{ml} \mathrm{h}^{-1}, \mathrm{TCD}=12.5 \mathrm{~cm}$, humidity $\left.=30 \% \mathrm{RH}\right)$. Applied voltages for steady state electrospinning are indicated in $\mathrm{kV}$.

wt\% Volume fraction acetic acid (\%)

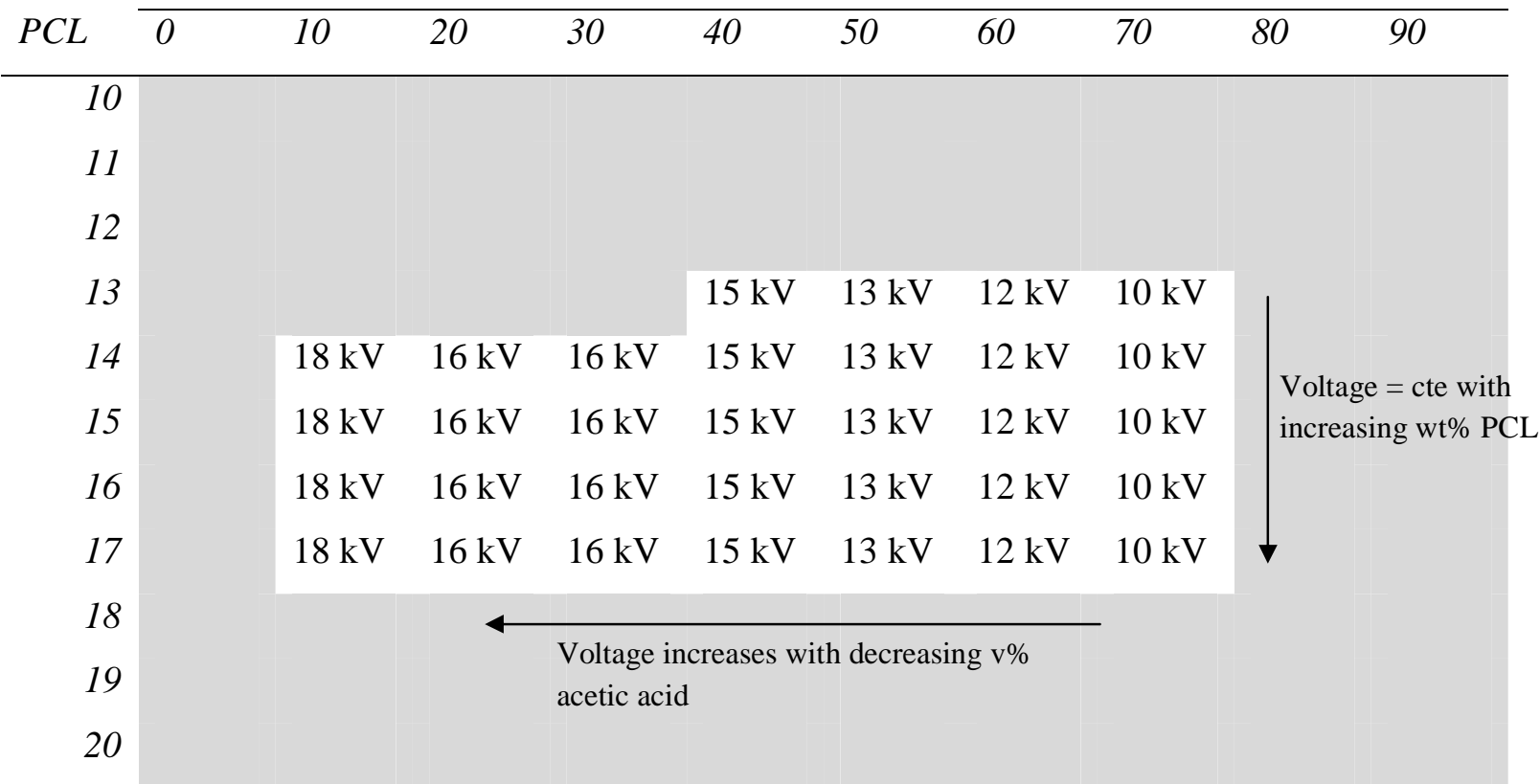

White region indicates steady state area.

Grey region indicates area where steady state spinning is not possible.

Table 4. Average fibre diameter and $\%$ deviation of $10 \mathrm{v} \%$ acetic acid as a function of the polymer concentration, produced at $10 \% \mathrm{RH}$ and $50 \% \mathrm{RH}$

\begin{tabular}{l|l|l|l|l}
\multicolumn{2}{l|}{} & \multicolumn{2}{l|}{$10 \% \mathrm{RH}$} & $50 \% \mathrm{RH}$ \\
\\
\hline wt\% PCL & diameter $(\mathrm{nm})$ & $\%$ deviation & diameter $(\mathrm{nm})$ & $\%$ deviation \\
\hline 12 & $297 \pm 49$ & 16 & $271 \pm 78$ & 29 \\
\hline 13 & $410 \pm 64$ & 16 & $355 \pm 126$ & 35 \\
\hline 14 & $443 \pm 79$ & 18 & $364 \pm 83$ & 23 \\
\hline
\end{tabular}




\begin{tabular}{l|l|l|l|l}
\hline 15 & $610 \pm 139$ & 23 & $392 \pm 106$ & 27 \\
\hline 16 & $798 \pm 188$ & 24 & $418 \pm 86$ & 21 \\
\hline 17 & $966 \pm 198$ & 21 & $463 \pm 108$ & 23 \\
\hline
\end{tabular}

